\title{
The nature of neuronal words and language
}

\author{
Morris Henry Baslow \\ Nathan S. Kline Institute for Psychiatric Research, Center for Neurochemistry, New York, USA; Baslow@nki.rfmh.org
}

Received 5 December 2009; revised 13 January 2010; accepted 30 January 2010.

\begin{abstract}
Individual neurons in the brain possess natural language in the form of energy-dependent action potentials or spikes (S) operating on a millisecond timescale that, along with pauses $(P)$ between spikes, constitute a two letter (S, P) "alphabet" that is used to generate meaningful frequency-encoded neuronal "words". These words are then used to transmit information to other neurons in the form of phrases consisting of two or more words that are contained within longer pause-delineated structured declarative sentences. In this article, the nature of neuronal words and language are described, and examples provided that illustrate the way in which neuronal language is used by the brain to interact with and interpret both its internal and external environments. It is hoped that a fuller understanding of the language used by neurons to communicate may lead to development of novel treatments for a number of human neuropathies.
\end{abstract}

Keywords: Biosemiotics; Brain; Cognition; Language; Learning; Memory; Neurons

\section{INTRODUCTION}

Semiotics is broadly defined as a study of signs, meanings and their significance in communication, and biosemiotics as a study that is based on the general assertion that all living organisms including cells are semiotic systems. While information processing in the brain is highly complex, each neuron uses a simple code mechanism for transmitting information. This is in the form of electrophysiological action potentials or spikes (S) of about a 1 millisecond (ms) duration that, along with pauses (P) between spikes constitute a two letter "alphabet" that generates meaningful frequency-encoded signals or neuronal S/P "words" [1]. The term "word" for neuronal activity in spikes/s has previously been used to describe the electrophysiological activity of the visual interneuron of the blowfly where each action potential (AP) was considered a "short" word and trains of AP's considered "longer" words [2]. In this article a neuronal word is defined as a single AP together with the total pause before the next AP; a phrase is defined as a group of two or more words, and a sentence as a temporal grouping of such words containing a subject, and a predicate that expresses what is stated about the subject [1]. All neuron codes, whether continuous trains of spikes that are characteristic of information transmitted at low frequencies, or bursts of spikes that are characteristic of information transmitted at high frequencies, are made up of interactions between spikes and pauses. There are two theories regarding how these spikes carry encoded information [3]. One is the "spike rate code" which suggests that information is carried in the average rate at which the neuron fires, and that the timing of each spike is random. The other is the "spike timing code" that suggests that specific information is carried not only in the average spike rate at which a neuron fires, but also in the precise timings between each spike. In this article, it is proposed that neurons transmit meaningful information not only in their spike rate and spike pause timing, but also in the spike duration or length $\left(\mathrm{S}_{\mathrm{L}}\right)$ and its relationship to the pause length $\left(\mathrm{P}_{\mathrm{L}}\right)$ between spikes. It is this relationship that constitutes a neuronal "S/P word", and adds an additional dimension to the potential richness of communication between neurons.

\section{DISCUSSIONS}

\subsection{Anatomy of a Neuronal Word}

The communication method used by the brain is generated at the cellular level where individual neurons transmit information to one another by generation a series of wave-like depolarizations. This depolarization's start at the plasma membrane of their cell bodies (soma) and pass along the plasma membranes of axon hillocks, axons and pre-synaptic dendrites. Each wave-like spike consists of two components, first, a rapid depolarization, involving the efflux of $\mathrm{K}^{+}$and influx of $\mathrm{Na}^{+}$at the plasma membrane down their respective intracellular/ extra cellular gradients, a process that requires little or 
no additional energy. This is followed by a re-polarization process that occurs within an absolute refractory period during which time the intracellular negative membrane $\mathrm{K}^{+} / \mathrm{Na}^{+}$potential is restored using energy derived from intracellular stores of adenosine triphosphate (ATP) via a plasma membrane surface enzyme, $\mathrm{Na}^{+} / \mathrm{K}^{+}$ATPase, in order to transport these ions against their respective gradients [4]. In single afferents of human mechanoreceptive sensory nerve fibers of the skin of the hand, spike times-to-peak were $0.12-0.45 \mathrm{~ms}$ with a mean of $0.21 \mathrm{~ms}$ [5]. While the depolarization process is pre-energized and trigger-ready, re-polarization is a slower enzyme-dependent process that is subject to rate regulation by all factors that can affect enzyme activity. These include enzyme, substrate, and end-product concentrations, focal ionic makeup, $\mathrm{pH}$, temperature as well as the presence of competitive and non-competitive inhibitors. All of these factors can affect the rate of re-polarization and the length of the absolute refractory period which in this study varied from $0.31-0.75 \mathrm{~ms}$ with a mean of $0.50 \mathrm{~ms}$ indicating that the energy consuming re-polarization period was 2.38 times longer than the depolarization period such that the length of the re-polarization period dominated the total spike period. In this study, the average length of a spike including the depolarization and longer re-polarization periods in the sensory nerve fibers was $0.71 \mathrm{~ms}$ with a range from 0.43-1.20 ms. The relationship between the depolarization and re-polarization periods of a single spike is illustrated in Figure 1. Since the depolarization is pre-primed and trigger ready, and the re-polarization period requires energy to reestablish ionic gradients, re-polarization is therefore subject to cellular control. Thus, the $\mathrm{S}_{\mathrm{L}}$ can be varied to incorporate information that is transmitted in the form of a $S_{L} / P_{L}$ ratio over and above information that transmitted by $\mathrm{Hz}$ and/or specific peak-to-peak inter-spike intervals. Data from [5].

During the spiking process which includes the absolute refractory period, and until the ionic gradients are reestablished, a second spike cannot be generated. In addition, following the absolute refractory period there is a relative refractory period where only a strong stimulus can generate a second AP, and following this period there is a period of longer pause with no electrophysiological activity. A spike including its absolute refractory period may vary, but an average spike-absolute refractive period length is about $1 \mathrm{~ms}$, and is followed by a relative refractory period of about $2 \mathrm{~ms}$ in duration [6]. This in turn is followed by a pause of varying lengths before the next spike is generated. Thus, there are two phases of signal generation, each consisting of two subcomponents. The total spike length $\left(\mathrm{S}_{\mathrm{L}}\right)$ is made up of the sum of the depolarization and absolute refractory (re-polarization) periods, and the total pause length $\left(\mathrm{P}_{\mathrm{L}}\right)$ is made up of the relative refractory period and the pause until the next spike is initiated. The total pause length can vary from 0 to approximately 10,000 ms under normal physiological conditions. Based on these neuronal spike and pause components, a single neuronal $\mathrm{S} / \mathrm{P}$ word has been defined as the sum of its total spike length and its total pause length in ms, and different words are characterized by differences in the ratio of its $S_{L}$ to its $P_{L}[1]$.

The spike-generation process that results in $\mathrm{S} / \mathrm{P}$ words is also is metabolically costly, calculated at $2.2 \times 10^{9}$ ATP molecules per spike [7], which requires that ATP supplies be constantly replenished or the timing of the spike-refractory periods will be altered, and meaningful frequency-encoded information lost [1]. An illustration of the components of a neuronal word as described is graphically presented in Figure 2.

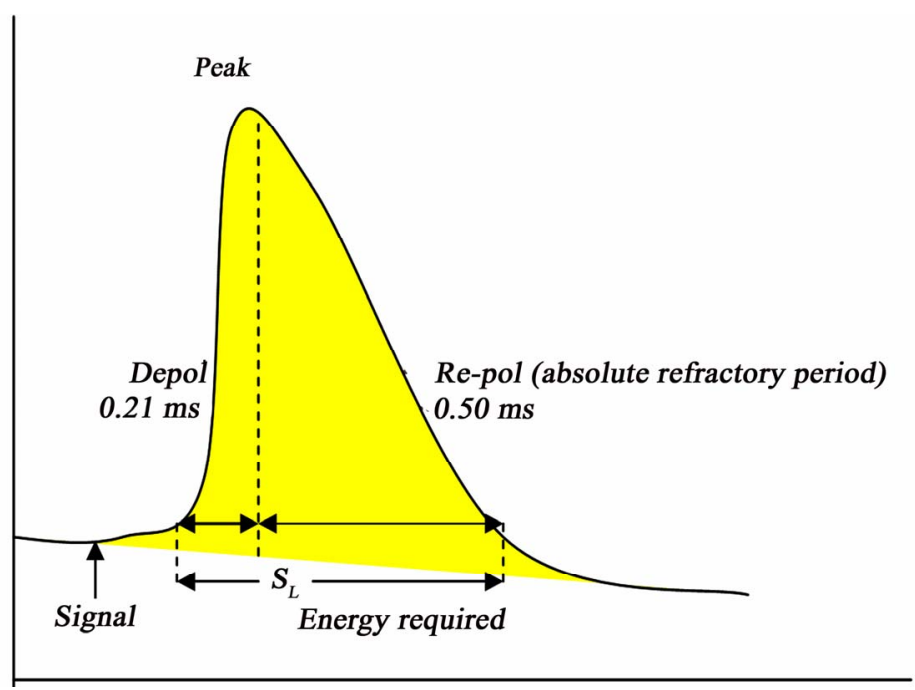

Figure 1. Cartoon showing the relative depolarization and repolarization times of a neuronal spike. 


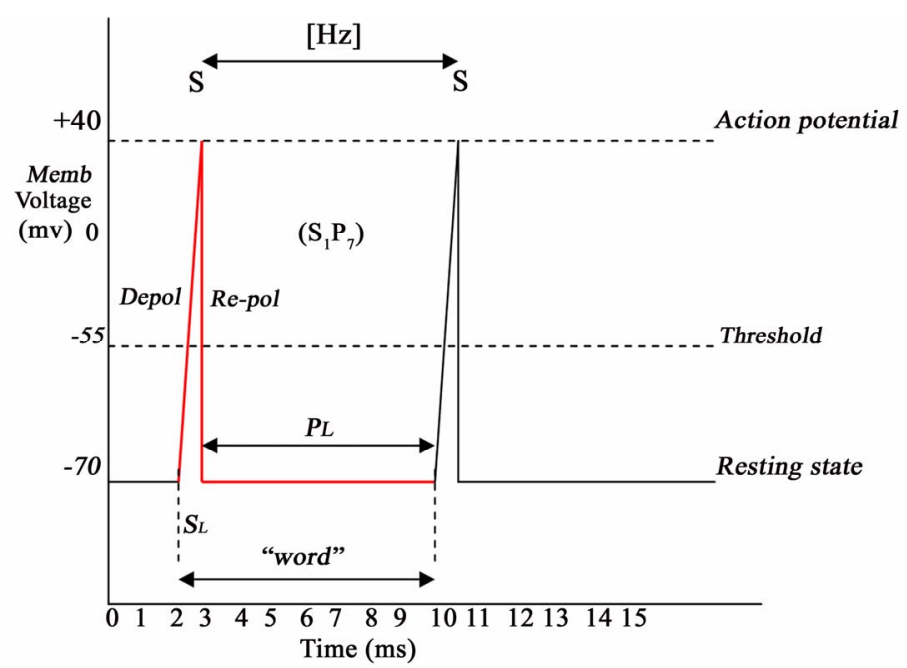

Figure 2. Cartoon showing the components of the neuronal word, $S_{1} P_{7}$.

In this illustration, each neuronal word $\left(\mathrm{S}_{1} \mathrm{P}_{7}\right)$ consists of a depolarizing spike $(0.5 \mathrm{~ms})$, an absolute refractory period when the plasma membrane is being re-polarized using ATP $(0.5 \mathrm{~ms})$ for a total spike length $\left(\mathrm{S}_{\mathrm{L}}\right)$ of $1.0 \mathrm{~ms}$; a relative refractory period where the neuron can be activated but only by a strong stimulus $(2.0 \mathrm{~ms})$; and a period of inactivity $(5.0 \mathrm{~ms})$. The spike frequency is $(1000 \mathrm{~ms} / 8 \mathrm{~ms})$ or $125 \mathrm{Hertz}(\mathrm{Hz})$. Unless the pause is terminated by a second spike within a physiologically relevant period, the word is incomplete and without any quantitative meaning. Thus, a meaningful phrase must consist of at least two words, and a sentence of at least one phrase. The word $\mathrm{S}_{1} \mathrm{P}_{7}$ presented in this cartoon reflects the S/P message generated upon exposure of the isolated salt receptor of the blowfly to a 3 molar $\mathrm{NaCl}$ solution [8].

\subsection{Conversion of Frequency in $\mathrm{Hz}$ to $\mathrm{S} / \mathrm{P}$ Words}

As shown in Figure 2, information contained in $\mathrm{Hz}$ format differs from that in $\mathrm{S} / \mathrm{P}$ word format in that in $\mathrm{Hz}$, the signal is a measure of the time between two spikes that is initiated at the peak of the first spike and is constituted by the re-polarization period of that spike, its relative refractory period, the pause until initiation of a second spike and the depolarization period of a second spike. In essence, the signal recorded in $\mathrm{Hz}$ splits a spike into its two components such that a spike in $\mathrm{Hz}$ is a composite formed from elements of two AP's. On the other hand, an S/P word as defined includes the depolarization and re-polarization components of a single spike, along with the relative refractory period and the pause until the next spike is initiated. However, the two formats are clearly related, and while $\mathrm{Hz}$ is a commonly used method of recording and describing neuronal activity, a reasonable estimation of the length of a neuronal word can also be derived from $\mathrm{Hz}$. Thus, from $\mathrm{Hz}$, the total time in $\mathrm{ms}$ of an average $\mathrm{S}+\mathrm{P}$ word can be determined: Total time per word: $\left(\mathrm{S}_{\mathrm{L}}+\mathrm{P}_{\mathrm{L}}\right)_{\mathrm{ms}}=1000 / \mathrm{Hz}$.

At a frequency of $100 \mathrm{~Hz}$, the mean $\mathrm{S}+\mathrm{P}$ word length would be $10 \mathrm{~ms}$. However, the total value in $\mathrm{ms}$ for an $\mathrm{S}$ $+\mathrm{P}$ word does not provide sufficient information to construct a specific neuronal S/P word. For this, one requires in addition either the total spike length $\left(\mathrm{S}_{\mathrm{L}}\right)$ or total pause length $\left(\mathrm{P}_{\mathrm{L}}\right)$. Thus, for a $\mathrm{S}_{\mathrm{L}}$ of 0.5 at $100 \mathrm{~Hz}$, the $\mathrm{S} / \mathrm{P}$ word would be $\mathrm{S}_{0.5} / \mathrm{P}_{9.5}$, for an $\mathrm{S}_{\mathrm{L}}$ of 1.0 , the $\mathrm{S} / \mathrm{P}$ word would be $\mathrm{S}_{1.0} / \mathrm{P}_{9.0}$, and for a $\mathrm{S}_{\mathrm{L}}$ of 1.5 , the $\mathrm{S} / \mathrm{P}$ word would be $\mathrm{S}_{1.5} / \mathrm{P}_{8.5}$, representing three different $\mathrm{S} / \mathrm{P}$ words out of a great number of possible $\mathrm{S} / \mathrm{P}$ words that are differentiated by the relative lengths of their spikes and pauses. It is important to note that all of these $\mathrm{S} / \mathrm{P}$ words are different and may transmit different meanings, but that all are being communicated at the same frequency of $100 \mathrm{~Hz}$. Clearly, a measure of frequency alone for neuronal communications cannot be physiologically accurate. When afferent neuronal messages are converted from electrophysiological to chemical and back into electrophysiological messages at synaptic interfaces for transmission to efferent neurons, it is highly likely that differences in the $\mathrm{S}_{\mathrm{L}} / \mathrm{P}_{\mathrm{L}}$ ratios are important elements in modulation of the messages at these interfaces. Since much of the published neuronal response data is presented in the form of $\mathrm{Hz}$, and while less accurate than actual $\mathrm{S} / \mathrm{P}$ words, in the absence of a measured $\mathrm{S}_{\mathrm{L}}$, and by using an average $S_{L}$ of 1.0, one can still derive useful information based on $\mathrm{Hz}$ about how neurons communicate with one another concerning the nature of their environment.

\subsection{Differences in Spike Rate, Spike Timing and Neuronal Word Codes in Information Transfer}

The spike rate code hypothesis proposes that information is processed in the form of the average time between 
spikes, and the spike timing code hypothesis proposes that information can also be contained in the differences in pauses between individual spikes, an analysis that can be used to identify harmonics and periodic oscillations in spike trains. Both of these hypotheses treat a spike as a point source and both are valid interpretations of recorded data. However, these hypotheses are mirror images of one another in that when viewed at the level of only two spikes, as presented in Figure 1, it is clear that the time between individual spikes treated as point sources, and the pause time between spikes will always be the same. On the other hand, the neuronal word code hypothesis as detailed above takes into consideration that individual spikes have a significant time dimension and shows that even at the level of only two spikes, there can be an enormous number of specific $\mathrm{S} / \mathrm{P}$ words that can be generated and used to transmit different kinds of information. This is because each neuronal word is formed by individual components of the AP process associated with spike generation, and differences in each component can alter the ratio between the total spike length and the total pause length. For the three examples provided above, $\mathrm{S}_{0.5} / \mathrm{P}_{9.5}, \mathrm{~S}_{1.0} / \mathrm{P}_{9.0}$ and $\mathrm{S}_{1.5} / \mathrm{P}_{8.5}$, their $\mathrm{S} / \mathrm{P}$ ratios are $0.052,0.111$ and 0.176 respectively, and all are capable of being transmitted at the same frequency $(\mathrm{Hz})$ where both the inter-spike time and pause time are the same. While all three hypotheses reflect frequency-based neuronal codes, the neuronal word code with its spike time dimension is the most physiologically realistic since it is the only one that identifies a mechanism whereby the AP can interact with the rate of depolarization-induced release of neurotransmitters from presynaptic vesicles. Thus, only the neuronal word code appears to have the potential for an enhanced richness in information transfer, especially at the low frequencies and short periods dictated by ongoing bioenergetic and temporal physiological constraints. Moreover, measurement of the ratios that comprise $\mathrm{S} / \mathrm{P}$ words may provide a new investigational tool, not available using the other "codes", with which to assess differences in neuronal function between normal and pathological conditions.

\subsection{Nature of Neuronal Language}

There are three components to neuronal language. First, neurons are "wired" in the sense that each neuron in the corpus occupies a specific place on a brain "map" of a given organism. Second, by virtue of its phenotype, each neuron sends specific kinds of messages for interpretation within the CNS network. For environmental sensing neurons, these may identify the qualitative nature of the messages being communicated such as where in the brain or corpus it originates, and whether the message is a general call for stored information, or whether it is from a specific region associated with some specific factor such as sound, light or availability of "glucose" (Glc). Lastly, the messages sent by neurons must also concern the quantitative nature of sensed information such as the importance of message itself, or the specific levels of light, sound, pain, pressure, stretch, or substance concentrations sensed. It is this last component, the quantitative nature of information within the brain, where specific frequency-encoded neuronal words appear to play an important role.

As an example, based on a recorded neuronal frequency of $100 \mathrm{~Hz}$, a neuronal spike with a total spike length of $1 \mathrm{~ms}$ and a total pause length of $9 \mathrm{~ms}$ would constitute the neuronal $\mathrm{S} / \mathrm{P}$ word $\left(\mathrm{S}_{1} \mathrm{P}_{9}\right)$ of $10 \mathrm{~ms}$ duration. When this word is repeated, it becomes a phrase. In the blowfly, this phrase corresponds to immersion of its isolated salt receptor in $2.0 \mathrm{M} \mathrm{NaCl}$ [8]. Based on using a value for total $\mathrm{S}_{\mathrm{L}}$ of $1 \mathrm{~ms}$, the specific words in "flyspeak" for immersion in additional $\mathrm{NaCl}$ concentrations of 0.5 and $1.0 \mathrm{M}$ are $\mathrm{S}_{1} \mathrm{P}_{18}(52 \mathrm{~Hz})$ and $\mathrm{S}_{1} \mathrm{P}_{12}(80 \mathrm{~Hz})$ respectively. In addition, if the $\mathrm{S}_{\mathrm{L}}$ is known along with the total $\mathrm{S}+\mathrm{P}$ time in $\mathrm{ms}$ derived from $\mathrm{Hz}$, the total "pause" time in ms can be derived using the following general relationship: $\mathrm{P}=\left[1000 \mathrm{~ms}-\left(\mathrm{Hz} \times \mathrm{S}_{\mathrm{L}}\right)\right] / \mathrm{Hz}$.

It has also been proposed, that the language of neurons can be written in any of a number of frequency-encoded formats including $\mathrm{Hz}, \mathrm{S} / \mathrm{P}$ and musical notations and can be translated into any of the oral, written or symbolic human languages as well [1]. Importantly, using artificial electronically generated frequencies that mimic the frequencies of recorded natural neuronal words, it has been demonstrated that it is possible not only to record these neuronal words, but also to communicate directly with the central nervous system (CNS) of rats. Where this has been done, the manufactured words have been shown to elicit the same behavioral responses in rats that would have been generated by exposure to a specific environmental stimulus [9].

\subsection{The Dictionary of Neuronal Words and their Representational Nature}

The dictionary of neuronal S/P words in an ms timeframe is relatively short, being limited at its upper level by the absolute and relative neuronal refractory periods and at its lower level by physiological requirements such as maintenance of the human heart rate at 68 beats $/ \mathrm{min}$ $(1.13 \mathrm{~Hz})$. With the average spike including an absolute refractory period of $1 \mathrm{~ms}$ duration followed by a relative refractory period of about $2 \mathrm{~ms}$, the highest possible frequency would be $\mathrm{S}_{1} \mathrm{P}_{2}$ or $333 \mathrm{~Hz}$. If the system were driven by a strong enough input eliminating the relative refractory period altogether, the highest possible frequency might be $\mathrm{S}_{1} \mathrm{P}_{0}$ or $1,000 \mathrm{~Hz}$.

Since the brain's primary form of communication, both internally and with the outside world, is in the form of these electrophysiological messages, it follows that neuronal words must also be highly representational in nature. For example, audible sound in many animals may range up to $20,000 \mathrm{~Hz}$ and visible light is in the 


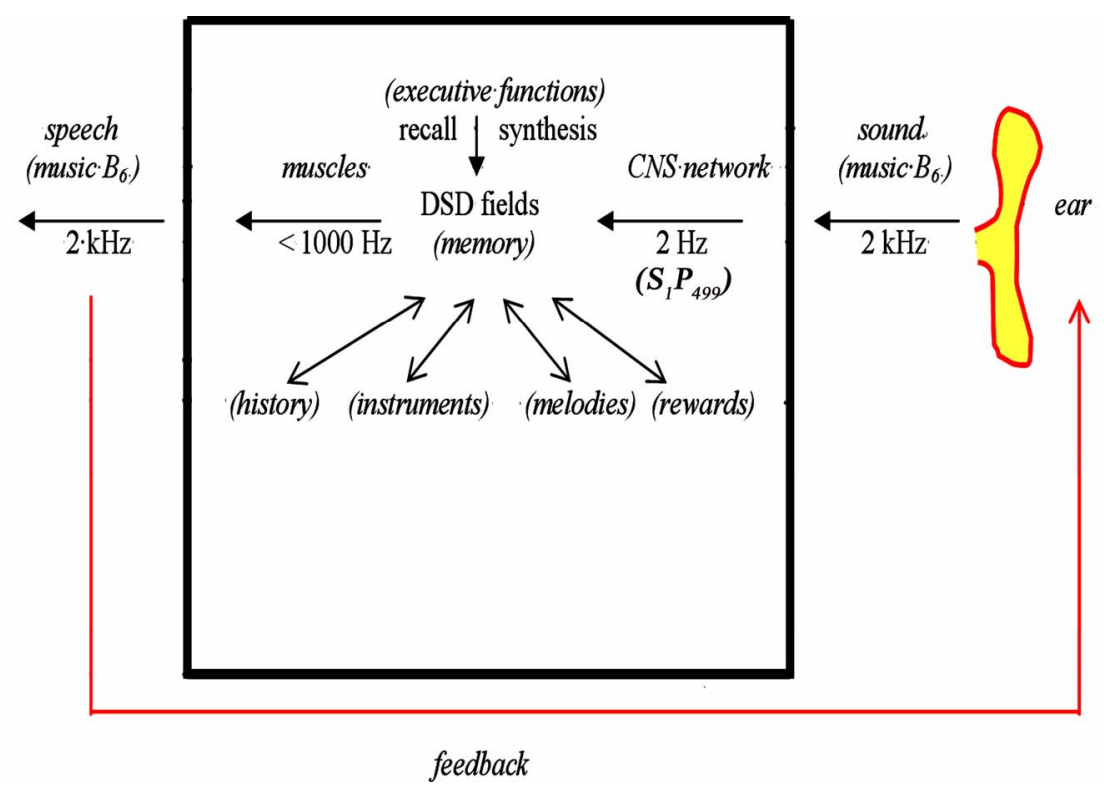

Figure 3. A “dark room" paradigm of brain function.

Table 1. List of several neuronal S/P words and their meanings.

\begin{tabular}{|c|c|c|c|c|c|}
\hline Organism & Sensor & Word & & Meaning & Reference \\
\hline $\begin{array}{l}\text { Blowfly } \\
\text { sensillum }\end{array}$ & salt & $\begin{array}{l}\mathrm{S}_{1} \mathrm{P}_{499} \\
\mathrm{~S}_{1} \mathrm{P}_{45} \\
\mathrm{~S}_{1} \mathrm{P}_{27} \\
\mathrm{~S}_{1} \mathrm{P}_{18} \\
\mathrm{~S}_{1} \mathrm{P}_{12} \\
\mathrm{~S}_{1} \mathrm{P}_{9} \\
\mathrm{~S}_{1} \mathrm{P}_{7}\end{array}$ & $\mathrm{NaCl}$ & $\begin{array}{l}0.10 \mathrm{M} \\
0.20 \\
0.25 \\
0.50 \\
1.00 \\
2.00 \\
3.00\end{array}$ & [8] \\
\hline $\begin{array}{c}\text { Ground beetle } \\
\text { Sensillum }\end{array}$ & salt & $\begin{array}{c}\mathrm{S}_{1} \mathrm{P}_{1000} \\
\mathrm{~S}_{1} \mathrm{P}_{71} \\
\mathrm{~S}_{1} \mathrm{P}_{29} \\
\mathrm{~S}_{1} \mathrm{P}_{23}\end{array}$ & $\mathrm{NaCl}$ & $\begin{array}{l}0.001 \mathrm{M} \\
0.01 \\
0.10 \\
1.00\end{array}$ & [11] \\
\hline $\begin{array}{l}\text { Hamster } \\
\quad \text { taste cells }\end{array}$ & acid & $\begin{array}{l}\mathrm{S}_{1} \mathrm{P}_{286} \\
\mathrm{~S}_{1} \mathrm{P}_{312} \\
\mathrm{~S}_{1} \mathrm{P}_{1999} \\
\mathrm{~S}_{1} \mathrm{P}_{4000}\end{array}$ & $\mathrm{pH}$ & $\begin{array}{c}2.5 \\
3.0 \\
4.3 \\
5.0\end{array}$ & {$[12]$} \\
\hline $\begin{array}{l}\text { Cat brain } \\
\text { hypothalamus } \\
\text { glucosensing }\end{array}$ & $\begin{array}{l}\text { glucose } \\
\text { steady-state } \\
\text { Glc i.v. } 30 \mathrm{~min}\end{array}$ & $\begin{array}{l}\mathrm{S}_{1} \mathrm{P}_{10000} \\
\mathrm{~S}_{1} \mathrm{P}_{2000}\end{array}$ & $\begin{array}{r}\text { normal } \\
\text { elevated }\end{array}$ & $\begin{array}{l}\text { Glc level } \\
\text { Glc level }\end{array}$ & [13] \\
\hline $\begin{array}{l}\text { Rat } \\
\quad \text { taste cells }\end{array}$ & quinine & $\mathrm{S}_{1} \mathrm{P}_{21}$ & quinin & ne $0.01 \mathrm{mM}$ & [9] \\
\hline $\begin{array}{l}\text { Rat brain } \\
\quad \text { hippocampal } \\
\text { neuron }\end{array}$ & sound & $\begin{array}{l}\mathrm{S}_{1} \mathrm{P}_{499} \\
\mathrm{~S}_{1} \mathrm{P}_{142}\end{array}$ & frequency & $\begin{array}{l}2 \mathrm{kHz} \\
10 \mathrm{kHz}\end{array}$ & [10] \\
\hline $\begin{array}{c}\text { Guinea pig brain } \\
\text { GABAergic } \\
\text { neurons }\end{array}$ & $\mathrm{H}_{2} \mathrm{O}_{2}$ & $\begin{array}{l}\mathrm{S}_{1} \mathrm{P}_{53} \\
\mathrm{~S}_{1} \mathrm{P}_{40}\end{array}$ & $\mathrm{H}_{2} \mathrm{O}_{2}$ & $\begin{array}{l}0.0 \mathrm{mM} \\
1.5\end{array}$ & [14] \\
\hline
\end{tabular}

range of $10^{14} \mathrm{~Hz}$. For the brain to comprehend its external environment, these frequencies must first be converted into representations of those wavelengths at less than $1000 \mathrm{~Hz}$, with the same meanings as the original signals, which can then be transmitted by neurons within the CNS network. These representations can also be "memorized" in the form of structural and biochemical changes in the dendrite-synapse-dendrite (DSD) fields 
between neurons, and later recalled to "imagine" the nature of the original wavelengths even without external input. For example, one can imagine "in the minds eye" the color "red" with the eyes closed, and with eyes open can also compare a newly observed representation of red with that which was previously seen and stored in memory. This phenomenon is illustrated in Figure 3 where a specific sound tone of $2 \mathrm{kHz}$ impinging on the ear is converted into a representational neuronal word at $2 \mathrm{~Hz}$ for CNS network processing.

In this illustration, the translation by a sense organ of the specific frequency-encoded environmental information for the approximate musical tone $\mathrm{B}_{6}(1975.53 \mathrm{~Hz})$ is illustrated. The sound sense organ first converts the tone into a brain frequency-encoded $\mathrm{S} / \mathrm{P}$ word representation for $\mathrm{B}_{6}$ at $2 \mathrm{~Hz}\left(\mathrm{~S}_{1} \mathrm{P}_{499}\right)$ that is then compared within the CNS network to auditory area DSD memory constructs. During this comparison related historical documents in other brain areas may also be probed for relevant information. Upon an executive command, appropriate muscles can also be activated to reproduce the $1975.53 \mathrm{~Hz}$ frequency, exporting it to another organism and also sending it back to the sense organ where it can be compared to the original tone. Importantly, the $\mathrm{S} / \mathrm{P}$ word for the tone $\mathrm{B}_{6}$ or any other musical tone can also be synthesized de novo by the brain from memory engrams without external input and can be "heard" within the brain as recalled sounds or melodies. All of these functions occur in a ms/sub-ms timeframe and apply to any other sensed parameter, whether derived internally or external to the brain. The specific auditory data presented in Figure 3 is adapted from rat experiments [10].

\subsection{Examples of Neuronal Words and their Meanings}

In Table 1 descriptions of some $\mathrm{S} / \mathrm{P}$ words and their meanings are presented. In each of these cases, the $\mathrm{S} / \mathrm{P}$ words have been derived from frequency data by using an average $\mathrm{S}_{\mathrm{L}}$ including an absolute refractory period of 1.0 $\mathrm{ms}$, and rounded to the nearest integer. However, it is also apparent that neurons can operate in a sub-millisecond timeframe [10], which is in keeping with the microsecond timeframe dictated by physiological demands and communication networking requirements of the brain.

\section{CONCLUSIONS}

In this paper it is proposed that neurons possess natural language in the form of specific neuronal words, phrases and sentences, and evidence is provided that when specific neuronal words are known, it is possible to mimic them and generate electronic words to communicate intelligently with the CNS. While most investigative recordings of neuronal activity are in the form of $\mathrm{Hz}$, the differences between $\mathrm{Hz}$ and word formats have been described, and a case has been made that the word format is the only format that can be physiologically associated with the release of specific quanta of neurotransmitters at synapses and is therefore more representative of the potential richness of information that can be transmitted by neurons. In addition, based on physiological limitations associated with the bioenergetic nature of neuronal AP's, it has been shown that much of the information about the external environment that is transmitted to the brain must first be reduced to a frequency-encoded representation of that information that can be communicated at $<1000 \mathrm{~Hz}$. These representations can be acted upon immediately, memorized when appropriate, and the memorized information recalled as needed in the form of such representations within the brain. Of note, in humans and other animals these internal representations can also be converted back into their original electromagnetic spectrum frequencies by externally re-creating the original environmental source such as by reproducing a particular memorized sound frequency. Finally, it is hoped that this paper will encourage the continued analysis of the nature of neuronal words and language, and that such studies will lead to additional development of novel electronic methods for communicating directly and intelligently with the CNS as has already been attempted in treatment of several human neuropathies [15]. With such specific frequency-encoded words as tools, it may be possible to alter or induce new behaviors, and thus lead to successful treatment stratagems for a variety of human psychological and neurological conditions.

\section{REFERENCES}

[1] Baslow, M.H. (2009) The languages of neurons; An analysis of coding mechanisms by which neurons communicate, learn and store information. Entropy, 11, 782-797.

[2] Borst, A. (2003) Noise, not stimulus entropy, determines neuronal information rate. Journal of Computational Neuroscence, 14, 23-31.

[3] Clifford, C.W. and Ibbotson, M.R. (2009) Response variability and information transfer in directional neurons of the mammalian horizontal optokinetic system. Visual Neuroscience, 17, 207-215.

[4] Baslow, M.H. and Guilfoyle, D.N. (2007) Using proton magnetic resonance imaging and spectroscopy to understand brain activation. Brain and Language, 102, 153-164.

[5] Brink, E.E. and Mackel, R.G. (1993) Time course of action potentials recorded from single human afferents. Brain, 116, 415-432.

[6] Berry II, M.J. and Meister M. (1998) Refractoriness and neural precision. Journal of Neuroscience, 18, 22002211.

[7] Lennie, P. (2003) The cost of cortical computation. Current Biology, 13, 493-497. 
[8] Gillary, H.L. (1966) Stimulation of the salt receptor of the blowfly. II. Temperature. Journal of General Physiology, 50 351-357.

[9] Di Lorenzo, P.M., Leshchinskiy, S., Moroney, D.N. and Ozdoba, J.M. (2009) Making time count: Functional evidence for temporal coding of taste sensation. Behavioral Neuroscience, 123, 14-25.

[10] Takahashi, S. and Sakurai, Y. (2009) Sub-millisecond firing synchrony of closely neighboring pyramidal neurons in hippocampal CA1 of rats during delayed nonmatching to sample task. Frontiers in Neural Circuits, 3(9)

[11] Merivee, E., Renou, M., Mand, M., Luik, A., Heidemaa, M. and Ploomi, A. (2004) Electrophysiological responses to salts from antennal chaetoid taste sensilla of the ground beetle Pterostichus aethiops. Journal of Insect Physiology, 50, 1001-1013.
[12] Gilbertson, T.A., Avenet, P., Kinnamon, S.C. and Roper, S.D. (1992) Proton currents through amiloride-sensitive $\mathrm{Na}$ channels in hamster taste cells. Journal of General Physiology, 100, 803-824.

[13] Anand, B.K., Chhina, G.S., Sharma, K.N., Dua, S. and Singh, B. (1964) Activity of single neurons in the hypothamic feeding centers: effect of glucose. American Journal of Physiology, 207, 1146-1154.

[14] Lee, C.R. and Rice, M.E. (2008) Hydrogen peroxide increases the excitability of substantia nigra pars reticulata GABAergic neurons. Society for Neuroscience Meeting, November 16, Program 179.2, Poster \# QQ37.

[15] George, M.S. and Aston-Jones, G. Noninvasive (2010) techniques for probing neurocircuitry and treating illness: Vagus nerve stimulation (VNS), transcranial magnetic stimulation (TMS) and transcranial direct current stimulation (tDCS). Neuropsychopharmacology, 35, 301-316. 